Ann. Biol. anim. Bioch. Biophys., I968, 8 (3), 4r9-429.

\title{
FACTEURS INTERVENANT DANS LA PRODUCTION DU SYSTĖME PROTÉOLYTIQUE CHEZ MICROCOCCUS CASEOLYTICUS
}

\author{
M. DESMAZEAUD et J. HERMIER \\ Station centrale de Recherches laitières et de Technologie des Produits animaux, \\ Centre national de Recherches zootechniques 78 - Jouy-en-Josas \\ Institut national de la Recherche agronomique
}

\section{SOMMAIRE}

Différents facteurs intervenant sur la croissance et la production de protéase exocellulaire de Micrococcus caseolyticus ont été étudiés : l'influence du chlorure de sodium, du glucose, du $\mathrm{pH} d \mathrm{du}$ milieu, de la température et de l'aération. Une technique de culture à $\mathrm{pH}$ constant est recommandée pour une production maximum de protéase exocellulaire.

En présence d'inducteur la production de protéase exocellulaire est parallèle à la croissance et a lieu pendant la phase logarithmique de croissance. La température optimum est de $30^{\circ} \mathrm{C}$, le $\mathrm{pH}$ optimum est de 7,o. L'aérobiose est une condition indispensable à la croissance. Le glucose permet une meilleure croissance mais son utilisation entraîne une acidification du milieu, inactivant irréversiblement l'enzyme : le $\mathrm{pH}$ doit être maintenu à une valeur de 7 . Le chlorure de sodium n'affecte pas"la croissance mais permet une apparition plus précoce de la protéase dans le surnageant de culture.

Les acides aminés induisent une très faible activité protéolytique exocellulaire mais n'exercent pas de répression. Les peptides induisent une forte activité protéolytique, qu'il y ait ou non croissance cellulaire. Les protéines ne sont inductrices que si la croissance s'effectue. Le glucose alors n'exerce pas d'effet répresseur.

\section{INTRODUCTION}

DEvoyod (Résultats non publiés) a montré que du lait dans lequel s'étaient multipliées certaines souches de microcoques fortement protéolytiques, contenait des substances de nature peptidique capables de stimuler la croissance dans le lait de certaines souches de Streptococcus cremoris (souche CNRZ 107), Str. thermophilus (souches $\mathrm{CNRZ} 7, \mathrm{CNRZ}$ I60, CNRZ 22). Ces substances étaient très probablement des produits de l'hydrolyse de la caséine du lait par un système protéolytique libéré au cours de la croissance du microcoque. Dans le but de caractériser ultérieurement ces peptides, il a 
été décidé de les préparer par action directe sur la caséine d'une protéase purifiée à partir d'une souche de Micrococcus caseolyticus reconnue comme stimulante de la croissance des bactéries lactiques.

Si l'on se réfère au genre $M i c r o c o c c u s$ au sens strict, donc en excluant $M$. lysodeikticus et "Coccus P " qui devraient être classées dans le genre Sarcina (CoLOBERT et RocQuET, 1957) nos connaissances sur les protéases des bactéries appartenant à ce genre se limitent à quelques caractéristiques de l'action sur la caséine de systèmes protéolytiques non purifiés produits par $M$. caseolyticus (POZNANSKI, LeNOrR et MocQUOT, I965) et par $M$. freudenreichii (HUSAIN et MCDonALD, I958). En revanche, les facteurs de la biosynthèse ont été bien étudiés dans le cas d'une protéase exocellulaire de $M$. freudenreichii. La production de l'enzyme est liée à la croissance et elle est stimulée par 1'addition de chlorure de sodium au milieu de culture (MCDoNALD, I96I). D'autre part, la synthèse de la protéase a lieu en l'absence de protéines ou de peptides, dont on aurait pu attendre une action inductrice ou stimulante sur la synthèse, mais la quantité de protéase obtenue est fonction de la nature de la source de carbone disponible dans le milieu de culture (McDonaId et Chambers, I966).

Dans le présent travail, nous avons étudié les facteurs de la biosynthèse d'un système protéolytique exocellulaire par $M$. caseolyticus. Nous montrerons en particulier que, contrairemenț à ce qui a été observé chez $M$. freudenreichii, ce système est inductible par un mélange de peptides.

\section{MATÉRIEL ET MÉTHODES}

\section{Souche bactérienne}

La souche $\mathrm{n}^{0} 96$ de Micrococcus caseolyticus utilisée dans ce travail, a été isolée à partir du lait de vache, lait recueilli par prélèvement stérile à la mamelle. La souche appartient au groupe 6 de la classification de BAIRD-PARKER (1963). Elle est conservée par repiquage mensuel sur Plate-Count Agar (Difco) et maintien à $4^{\circ} \mathrm{C}$.

\section{Conditions de culture}

Pour tous les essais autres que ceux relatifs à l'influence de la source azotée et ceux de culture à $\mathrm{pH}$ constant, $M$. caseolyticus est cultivé à $30^{\circ} \mathrm{C}$ dans le milieu liquide " $\mathrm{TG}$ " dont la composition pour un litre est la suivante : tryptone (Difco) Io g, glucose $5 \mathrm{~g}$, extrait de levure (Difco) $5 \mathrm{~g}$, chlorure de sodium $5 \mathrm{~g}$, tampon phosphate de potassium $0,134 \mathrm{M}$ à pH $7, \mathrm{I}$ 000 ml. Les modifications apportées à ces conditions au cours des essais sont indiquées dans le texte. Le milieu est inoculé avec $4 \mathrm{p}$.cent volume à volume d'une suspension de cellules de $M$. caseolyticus. Cette suspension est obtenue à partir d'une culture à $30^{\circ} \mathrm{C}$ pendant $18 \mathrm{~h}$ dans un milieu " $T G$ ", qui est diluée avec du milieu non ensemencé de telle façon que sa densité optique à $65^{\circ} \mathrm{m} \mu$ soit ramenée à $\mathrm{r}$,o. Le milieu ensemencé est incubé dans des tubes en verre non agités contenant ro $\mathrm{ml} \mathrm{de} \mathrm{milieu.}$

Dans le cas de l'étude de l'influence de la source azotée, $M$. caseolyticus est cultivé à $30^{\circ} \mathrm{C}$ dans le milieu liquide " $A G$ » qui a la composition suivante pour un litre : casamino acids (Difco) ro g, glucose $5 \mathrm{~g}$, extrait de levure (Difco) I $\mathrm{g}$, chlorure de sodium $5 \mathrm{~g}$, tampon phosphate de potassium $0,067 \mathrm{M}$ à $\mathrm{pH} .7,0, \mathrm{I}$ 000 $\mathrm{ml}$. A ce milieu on ajoute le composé azoté essayé à raison de $\mathrm{Iog}$ par litre de milieu. Ce milieu est contenu dans des erlenmeyers d'une capacité de $500 \mathrm{ml}$, à raison de $100 \mathrm{ml}$ de milieu par récipient. Il est inoculé avec une suspension de cellules obtenues par centrifugation à $4^{\circ} \mathrm{C}$ d'une culture à $30^{\circ} \mathrm{C}$ pendant $\mathrm{I} 8 \mathrm{~h}$ dans le milieu $\mathrm{AG}$ lavées trois fois par de l'eau physiologique à $9 \mathrm{~g}$ de chlorure de sodium par litre et remises en suspension dans de l'eau physiologique à $9 \mathbf{g}$ de chlorure de sodium par litre. Les autres conditions de l'inoculation sont indiquées dans le texte. Les erlenmeyers sont incubés à $30^{\circ} \mathrm{C}$ sur un agitateur alternatif oscillant à roo translations par minute. 
Dans le cas des cultures à $\mathrm{pH}$ constant, le milieu de culture a la composition suivante pour un litre : tryptone (Difco) $15 \mathrm{~g}$, glucose $40 \mathrm{~g}$, extrait de levure (Difco) $10 \mathrm{~g}$, chlorure de sodium $6 \mathrm{~g}$ et:

- soit du tampon phosphate de potassium $0,067 \mathrm{M} \mathrm{à} \mathrm{pH} \mathrm{7,0,} \mathrm{I} 000 \mathrm{ml}$ (milieu " TG " enrichi);

- soit chlorure de calcium $\left(\mathrm{Cl}_{2} \mathrm{Ca}, 2 \mathrm{H}_{2} \mathrm{O}\right) 0,6 \mathrm{~g}$, Tris.(hydroxyméthyl) aminométhane $4,2 \mathrm{~g}$, acide maléique $3,2 \mathrm{~g}$, eau distillée I ooo $\mathrm{ml}$ ( $\mathrm{pH}$ final 7,0 ) (Milieu " TGCa ").

Un ballon d'une capacité de $2 \mathrm{l}$ et contenant $\mathrm{I} 55^{\circ 0} \mathrm{ml}$ est inoculé dans les mêmes conditions que le milieu TG et incubé à $30^{\circ} \mathrm{C}$ dans un bain-marie. Le milieu est fortement agité par la rotation d'un barreau magnétique et aéré par barbottage d'air stérile $(0,5$ litre par minute). Le maintien du $\mathrm{pH}$ du milieu à la valeur de $7 \pm 0,05$ est obtenu par l'addition automatique d'une solution de soude $5 \mathrm{~N}$ commandée par un titrateur Metrohm (E 361 ) en fonction des indications fournies par une électrode combinée Metrohm plongeant dans le milieu de culture.

Les milieux et les récipients de culture sont stérilisés par autoclavage à $120^{\circ} \mathrm{C}$ pendant 20 minutes. Le glucose et les protéines en solutions concentrées sont stérilisés par filtration sur filtre Seitz et ajoutés au milieu de culture juste avant son utilisation.

\section{Méthodes et techniques de mesure}

La croissance bactérienne est suivie par lecture au spectrophotomètre Beckman DB de la densité optique à $65^{\circ} \mathrm{m} \mu$ du milieu de culture dans une cuve en verre de $\mathrm{I} \mathrm{cm}$ de chemin optique.

Le glucose est dosé par la méthode à l'orcinol de SoERENSEN et HAUGAARD (1933). Les valeurs du $\mathrm{pH}$ dans le milieu de culture sont déterminées avec un $\mathrm{pH}$ mètre E. I. L. (Electrode Ingold).

L'activité protéolytique du milieu de culture est mesurée en déterminant la concentration des produits de la réaction d'hydrolyse de la caséine qui sont solubles dans l'acide trichloracétique à $6 \mathrm{p}$. IOo (ANSON, I938). A 9 ml d'une solution à 2 p. Ioo de caséine isoélectrique en tampon Tris-(bydroxyméthyl) aminométhane- $\mathrm{HCl} 0,05 \mathrm{M}$ à $\mathrm{pH} 7,5$ on ajoute $\mathrm{I} \mathrm{ml}$ du milieu de culture préalablement centrifugé à $8000 \mathrm{~g}$ pendant $3^{\circ} \mathrm{mn}$ à $4^{\circ} \mathrm{C}$ pour éliminer les cellules bactériennes.

Après mélange et maintien à $30^{\circ} \mathrm{C}$ pendant $10 \mathrm{mn}$, la réaction est arrêtée par addition de $10 \mathrm{ml}$ d'une solution d'acide trichloracétique à $12 \mathrm{p}$. 100 . Après 20 minutes de contact, le mélange est passé sur filtre Durieux $\mathrm{n}^{\circ}$ I I I et la teneur en composés solubles du filtrat est déterminée par son absorption à $275 \mathrm{~m} \mu$ mesurée dans une cuve en quartz de un $\mathrm{cm}$ de chemin optique à l'aide d'un spectrophotomètre Beckman DB. Le blanc du dosage est constitué par le filtrat du mélange réactionnel après précipitation par l'acide trichloracétique dès l'addition du milieu de culture à la solution de caséine.

L'unité d'activité protéolytique est définie comme le changement de $0,00 \mathrm{I}$ unité de densité optique à $275 \mathrm{~m} \mu$ dans les conditions décrites ci-dessus par minute et par $\mathrm{ml}$ de milieu de culture. L'activité spécifique est définie comme le rapport de l'activité protéolytique sur la densité optique à $650 \mathrm{~m} \mu$ de la culture.

L'activité protéolytique intracellulaire est mesurée sur des extraits cellulaires préparés par broyage des cellules bactériennes dans un omni-mixer Sorvall; la cuve de broyage contient I $^{12}$ cellules mises en suspension dans $3 \mathrm{ml}$ de tampon Tris-(hydroxyméthyl) aminométhane $0,05 \mathrm{M}$ à $\mathrm{pH} \mathrm{7,5}$ et 8 grammes de perles de verre de 180 microns de diamètre, la durée du broyage est de 180 secondes pour une vitesse de rotation de 30 ooo tours à la minute. Les perles de verre sont ensuite éliminées par filtration sur filtre à billes de verre sous un vide léger et rincées avec $5 \mathrm{ml}$ de tampon Tris $0,05 \mathrm{M}$ à pH 7 ,

Les filtrats sont ensuite centrifugés à $4^{\circ} \mathrm{C}$ pendant $3^{\circ} \mathrm{mn} \mathrm{à} 27000 \mathrm{~g}$ afin d'eliminer les fragments cellulaires. L'activité protéolytique de ces filtrats est mesurée dans les conditions décrites pour la mesure de l'activité protéolytique exocellulaire.

\section{RÉSULTATS}

\section{Etudes préliminaires}

La croissance à $30^{\circ} \mathrm{C}$ de $M$. caseolyticus dans le milieu TG est relativement lente puisqu'elle se poursuit pendant $60 \mathrm{~h}$ (fig. I). Une activité protéolytique apparaît dans le milieu de culture dès le début de la croissance, passe par un maximum à $40 \mathrm{~h}$ d'incubation pour diminuer ensuite lentement. Le pH du milieu décroît régulièrement par suite de la fermentation du glucose. Après 20 heures comme après 40 heures de culture l'activité protéolytique intracellulaire reste 60 fois inférieure à l'activité protéolytique exocellulaire. 
L'influence du pH du milieu de culture et celle de la source azotée principale sur la production du système protéolytique ont été étudiées de façon approfondie et seront exposées dans les paragraphes suivants. D'autres facteurs, tels que la température d'incubation, la concentration du glucose et du chlorure de sodium dans le milieu, n'ont fait l'objet que d'une étude préliminaire portant sur des cultures incubées sans agitation pendant 16 heures.

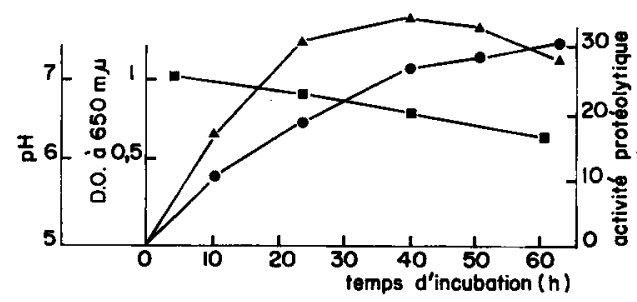

FIG. I. - Croissance et production du système protéolytique exocellulaire de M. caseolyticus dans le milieu $T G$

-_ : densité optique du milieu de culture

A-A : activité protéolytique

- : pH du milieu de culture

\section{Infuence de la température.}

Comme le montre le tableau I, l'activité protéolytique la plus élevée est obtenue a $30^{\circ} \mathrm{C}$, non seulement en valeur absolue, mais aussi quand elle est rapportée à la croissance (activité spécifique). En revanche, l'optimum de c1oissance se situe à $37^{\circ} \mathrm{C}$. Ce phénomène est analogue à celui observé chez $M$. lysodeikticus (GorinI et FromaGEOT, I950). On notera de plus qu'une croissance faible est possible à $10^{\circ} \mathrm{C}$ mais sans production du système protéolytique.

\section{TABLEAU I}

Influence de la température de culture sur la production du système protéolytique dans le milieu $T G$

\begin{tabular}{c|c|c|c}
\hline $\begin{array}{c}\text { Température } \\
\left({ }^{\circ} \mathrm{C}\right)\end{array}$ & $\begin{array}{c}\text { Unités d'activité } \\
\text { protéolytique }\end{array}$ & $\begin{array}{c}\text { Unités } \\
\text { de densité optique }\end{array}$ & $\begin{array}{c}\text { Activité } \\
\text { spécifique }\end{array}$ \\
\hline & 0 & 0,03 & 0 \\
10 & 2,7 & 0,40 & 6,8 \\
19 & 11 & 0,97 & 12 \\
25 & 28 & 1,12 & 25 \\
30 & 6,5 & 1,17 & 5,6 \\
37 & & & \\
\hline
\end{tabular}

\section{Influence du glucose.}

En l'absence de glucose, la croissance est beaucoup plus lente mais la production du système protéolytique est encore plus ralentie, comme le montre le tableau 2. En revanche, quand la concentration du glucose dans le milieu est portée de 5 à ro $\mathrm{g}$ par litre, on n'observe aucun changement dans la vitesse de croissance nu la production 
du système protéolytique. Le glucose n'exerce donc pas d'effet inhibiteur sur la synthèse de l'enzyme, contrairement à ce qui a été constaté chez $M$. lysodeikticus (GoRINI et Fromageot, I950) ou dans le genre Arthrobacter (Hofsten et TJEDER, I965).

TABLEAU 2

Influence de la concentration du glucose et du chlorure de sodium dans le milieu TG sur la production du système protéolytique

\begin{tabular}{c|c|c|c|c}
\hline $\begin{array}{c}\text { Concentration } \\
\text { en glucose } \\
\text { (en g/l) }\end{array}$ & $\begin{array}{c}\text { Concentration } \\
\text { en NaCl } \\
\text { (en } \mathrm{g} / \mathrm{l})\end{array}$ & $\begin{array}{c}\text { Unités d'activité } \\
\text { protéolytique }\end{array}$ & $\begin{array}{c}\text { Unités } \\
\text { de densité optique }\end{array}$ & $\begin{array}{c}\text { Activité } \\
\text { spécifique }\end{array}$ \\
\hline 0 & 5 & 2,1 & 0,35 & 6 \\
5 & 5 & 24 & 1,16 & 21 \\
10 & 5 & 25 & 1,16 & 21 \\
5 & 0 & 13 & 1,16 & 11 \\
5 & 12 & 23 & 1,14 & 20 \\
5 & 72 & 25 & 1,15 & 22 \\
\hline
\end{tabular}

\section{Influence du chlorure de sodium.}

Puisqu'il avait été montré chez $M$. freudenreichii que le chlorure de sodium favorisait la libération de protéase dans le milieu de culture (MCDONALD, I96I), la présence de ce sel a été prévue dans la composition du milieu TG. Dans un milieu sans sel, la vitesse de croissance n'est pas modifiée mais l'activité protéolytique dans le milieu diminue d'environ 50 p. roo (tabl. 2). On retrouve donc bien chez $M$. caseolyticus l'effet stimulant du chlorure de sodium mis en évidence chez $M$. freudenreichii. L'augmentation de la concentration de ce sel jusqu'à $72 \mathrm{~g}$ par litre, n'apporte aucun changement dans la croissance ou l'activité protéolytique dans le milieu TG (tabl. 2), alors que la croissance de $M$. freudenreichii est fortement inhibée par de telles concentrations (McDonald, Ig6I).

\section{Influence $d u p H d u$ milieu de culture}

Quand on réduit la concentration du tampon phosphate dans le milieu TG à $0,0067 \mathrm{M}$, on constate que la croissance est d'abord plus rapide que dans le milieu TG non modifié, puis fortement ralentie après 30 heures d'incubation (fig. 2). Par suite

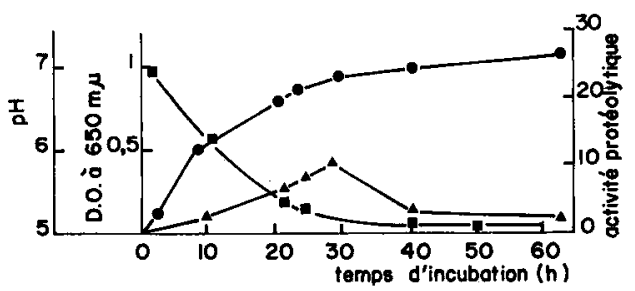

Fig. 2. - Influence de l'abaissement de la concentration en tampon phosphate du milieu TG sur la croissance et la production du système protéolytique de M. caseolyticus

- - densité optique du milieu de culture

- - activité protéolytique

- : : $\mathrm{pH}$ du milieu de culture 
du faible pouvoir tampon du milieu, le $\mathrm{pH}$ décroît rapidement pour atteindre la valeur de 5,I en fin de culture. L'activité protéolytique du milieu de culture augmente nettement moins vite que dans le milieu TG non modifié puis décroît rapidement après 30 heures d'incubation.

Il apparaît donc que la production du système protéolytique chez $M$. caseolyticus est reliée à l'évolution du $\mathrm{pH}$ du milieu de culture. Cette relation avec le $\mathrm{pH}$ a été confirmée en changeant le $\mathrm{pH}$ initial du milieu TG par modification de la composition du tampon, sans changer sa concentration. Dans la figure 3 sont réparties les valeurs

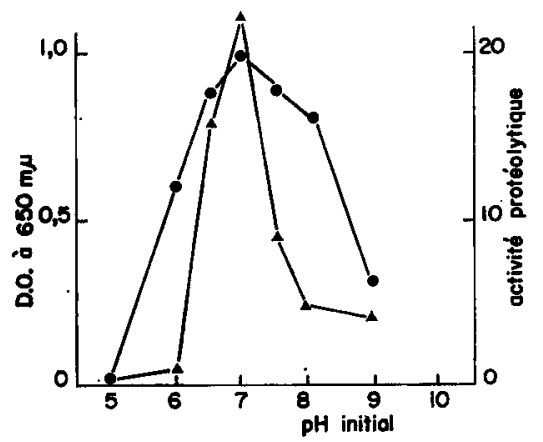

FIc. 3. - Influence du $p H$ initial du milieu $T G$ sur $a$ croissance et production du systeme protéolytique - - activité optique du milieu de culture

$\sim \longrightarrow$ : activité protéolytique

de la densité optique du milieu après 24 heures d'incubation, en fonction du $\mathrm{pH}$ initial du milieu de culture. Les vitesses maximales de croissance et de production du système protéolytique sont obtenues à pH 7. Quand on s'éloigne de cette valeur, la production diminue beaucoup plus rapidement que la croissance.

On peut donc espérer favoriser la production du système protéolytique en maintenant le $\mathrm{pH}$ du milieu de culture à la valeur de 7 , par neutralisation avec de la soude. Des cultures effectuées dans ces conditions en milieu TG ont montré qu'en effet, il en

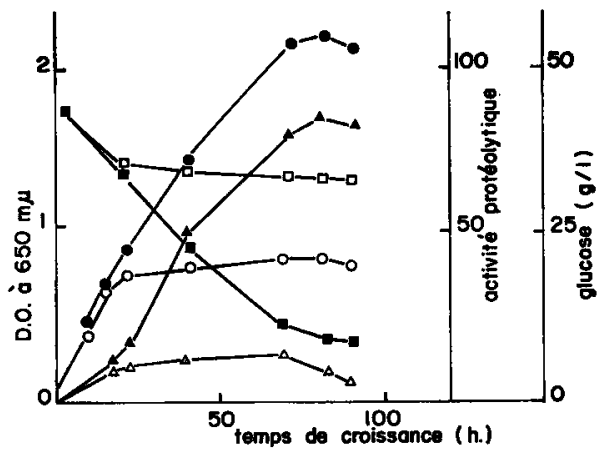

Fig. 4. - Croissance et production du système protéolylique dans le milieu $T G$ enrichi maintenu d $p H 7.0$

-— - -0 : densité optique du milieu de culture

$\Delta-\Delta \Delta \_\Delta$ : activité protéolytique

- - $\square \longrightarrow \square$ : concentration en glucose

- - a culture aérée

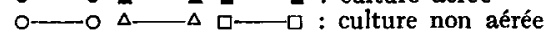


est bien ainsi et que la valeur maximale de la croissance est, elle aussi, plus élevée que dans le milieu neutralisé. Quand on augmente la concentration des constituants du milieu TG autres que le tampon phosphate, on constate que les valeurs maximales de la croissance et de l'activité protéolytique s'accroissent. Dans la figure 4 sont montrées la croissance et la production du système protéolytique dans le milieu "TG enrichi " dont tous les constituants sont en excès (sa composition est donnée dans le chapitre "Matériel et Méthodes "). L'augmentation de l'activité protéolytique est parallèle à celle de la densité optique de la culture et s'arrête sensiblement en même temps. Quand on supprime l'aération du milieu par barbottage d'air, la croissance s'effectue d'abord à la même vitesse puis s'arrête très précocement. Là encore l'évolution de l'activité protéolytique est parallèle à celle de la croissance. On notera en outre, que la consommation du glucose suit l'évolution de la croissance que le milieu de culture soit aéré ou non.

Comme on le verra dans la deuxième partie de ce travail, le composant principal du système protéolytique produit par $M$. caseolyticus est stabilisé par l'ion calcium. C'est pourquoi l'essai de culture à $\mathrm{pH}$ constant a été repris en ajoutant du chlorure de calcium au milieu de culture, après avoir remplacé le tampon phosphate par du tampon Tris-maléate (Milieu TGCa). Dans ces conditions (fig. 5), la croissance est plus

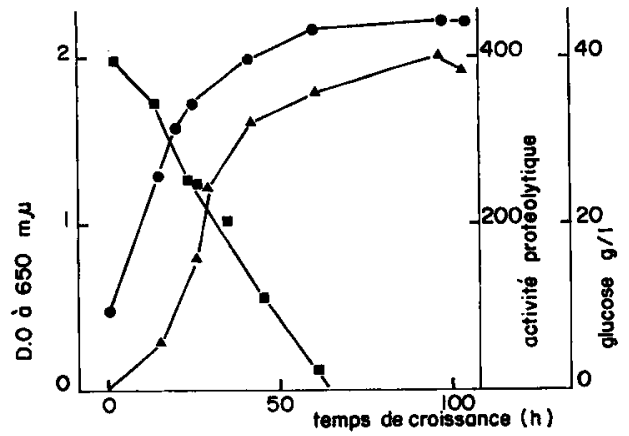

FIG. 5. - Croissance et production du système protéolytique dans un milieu enrichi en calcium et maintenu d $p H \quad 7$

-—— : densité optique du milieu de culture

-_- : activité protéolytique

- - : concentration en glucose

rapide, mais s'arrête néanmoins à la même valeur de densité optique ; cependant à la fin de la croissance, tout le glucose a été consommé, contrairement à ce qui est observé en absence de calcium ; la synthèse du système protéolytique est parallèle à la croissance, puis se poursuit lentement après son arrêt; l'activité protéolytique du milieu est supérieure à 4 fois celle obtenue en absence de calcium.

\section{Influence de la source d'azote}

Quand on remplace la tryptone du milieu TG par un mélange d'acides aminés (Casamino acids), 1'activité protéolytique dans le mileu de culture ne représente que ro $p$. cent de celle observée dans le milieu TG, alors que la vitesse de croissance n'est pas modifiée. Donc un milieu où la source d'azote principale est constituée par ce mélange d'acides aminés (milieu $\mathrm{AG}$ ) peut être utilisé pour déterminer l'influence des composés azotés sur la synthèse dı système protéolytique. 
Au cours de la croissance de Micrococcus caseolyticus dans le milieu AG inoculé avec $3.10^{9}$ cellules par $\mathrm{ml}$, la synthèse du système protéolytique est stimulée par l'addition soit d'un hydrolysat enzymatique de protéines (Bacto-tryptone, Trypticase, Bacto-peptone) soit d'une protéine (caséine, $\beta$-lactoglobuline, sérum-albumine), 1'effet le plus marqué étant observé avec la caséine (tabl. 3). Cette addition d'une source azotée supplémentaire au milieu de culture n'entraîne pas de variation dans la vitesse de croissance.

TABLEAU 3

Influence des peptones et des protéines

sur la production du système protéolytique dans le milieu $A G$

\begin{tabular}{|c|c|c|c|}
\hline \multirow{3}{*}{$\begin{array}{l}\text { Composés azotés } \\
(1 \mathrm{~g} / \mathrm{l})\end{array}$} & \multicolumn{3}{|c|}{ Unités d'activité protéolytique } \\
\hline & \multicolumn{3}{|c|}{ Temps d'incubation } \\
\hline & $2 \mathrm{~h}$ & $4 \mathrm{~h}$ & $6 \mathrm{~h}$ \\
\hline - & 1 & 4 & 7 \\
\hline Bacto-tryptone ......... & 5 & 20 & 40 \\
\hline Trypticase ............ & 8 & 26 & 41 \\
\hline Bacto-peptone..$\ldots \ldots \ldots$ & 7 & 26 & 38 \\
\hline Caséine $\ldots \ldots \ldots \ldots \ldots$ & 10 & 40 & 65 \\
\hline B-lactoglobuline ......... & 7 & 22 & 50 \\
\hline Sérum-albumine ........ & 7 & 25 & 29 \\
\hline
\end{tabular}

Cet effet stimulant des protéines ou de leur hydrolysat enzymatique pourrait être attribué à une induction par ces composés de la biosynthèse du système protéolytique. Si tel était bien le cas, cet effet d'induction devrait être retrouvé avec des cellules non proliférantes. Comme le montre le tableau 4, des cellules de $M$. caseolyticus produites dans le milieu $\mathrm{AG}$ et resuspendues après lavage dans une solution de chlorure de sodium à $5 \mathrm{~g} / 1$ dans du tampon phosphate $0,067 \mathrm{M}$ à $\mathrm{pH} 7,0$, à raison de $10^{10}$

TABLEAU 4

Infuence des composés azotés sur la production du système protéolytique chez les cellules non proliférantes de M. caseolyticus

\begin{tabular}{|c|c|c|c|c|}
\hline \multirow{3}{*}{$\begin{array}{l}\text { Composés azotés } \\
\qquad(10 \mathrm{~g} / \mathrm{l})\end{array}$} & \multicolumn{4}{|c|}{ Unités d'activité protéolytique } \\
\hline & \multicolumn{4}{|c|}{ Temps d'incubation } \\
\hline & $0 \mathrm{mn}$ & $45 \mathrm{mn}$ & $90 \mathrm{mn}$ & $150 \mathrm{mn}$ \\
\hline $\begin{array}{l}\text { Caséine (ou } \beta \text {-lactoglobu- } \\
\text { line, ou sérum-albumine) }\end{array}$ & & & & \\
\hline Bacto-tryptone ........ & 0 & 11 & 22 & 43 \\
\hline Trypticase ........... & 0 & 10 & 24 & 30 \\
\hline Bacto-peptone.$\ldots \ldots \ldots$. & 0 & 12 & 28 & 35 \\
\hline Casamino acids $\ldots \ldots \ldots$ & 0 & 0,41 & 0,62 & 0,70 \\
\hline
\end{tabular}


cellules par $\mathrm{ml}$, ne synthétisent pas le système protéolytique. Il en est de même quand on ajoute à cette solution de la caséine ou une autre protéine telle que la sérum albumine ou la $\beta$-lactoglobuline. Par contre, l'addition d'un hydrolysat trypsique de caséine (Bacto-tryptone, Trypticase) ou d'un hydrolysat pepsique (Bacto-peptone), qui contient un mélange de peptides et d'acides aminés, déclenche la biosynthèse qui se poursuit de façon sensiblement linéaire pendant les 90 premières minutes d'incubation. La biosynthèse est aussi observée, mais elle est alors très lente, quand l'hydrolysat enzymatique de caséine est remplacé par un hydrolysat acide de caséine (Casamino acids) qui renferme seulement des acides aminés. Cette expérience démontre donc que la synthèse du système protéolytique est inductible par un mélange de peptides ou dans une très faible mesure par un mélange d'acides aminés.

\section{DISCUSSION}

L'examen de l'ensemble des courbes de production du système protéolytique exocellulaire de $M$. caseolyticus montre que ce système est presque exclusivement produit au cours de la croissance. Toutefois, suivant les conditions de culture la quantité maximale d'enzyme est obtenue soit avant la fin de la croissance, soit au moment où s'arrête la croissance, soit après.

Comme on le verra dans la deuxième partie de ce travail, le composant principal du système protéolytique exocellulaire de $M$. caseolyticus n'est stable en absence d'ions calcium que dans une zone très étroite de $\mathrm{pH}$ comprise entre 7 et 7,5. Or le $\mathrm{pH}$ d'un milieu de culture, initialement de 7 , décroît au cours de la croissance, d'autant plus vite que le milieu est moins tamponné. Le système protéolytique s'inactive donc partiellement après sa libération dans le milieu de culture, si bien que le maximum apparent de sa production se situe avant la fin de la croissance d'autant plus précocement que la concentration du tampon dans le milieu de culture est moins élevée. L'influence du $\mathrm{pH}$ initial du milieu de culture peut être interprétée de la même façon, puisque la vitesse de production du système protéolytique est maximale quand le $\mathrm{pH}$ initial du milieu de culture est de 7 . Cependant, le $\mathrm{pH}$ du milieu agit aussi autrement que par l'intermédiaire de la stabilité du système protéoly tique puisque, dans un milieu à $\mathrm{pH} 7,5$, la vitesse de production est beaucoup plus faible qu'à $\mathrm{pH} 6,5$, bien que le composant principal du système soit plus stable à $\mathrm{pH} 7,5 \mathrm{qu}^{\prime} \mathrm{à} \mathrm{pH} 6,5$.

Dans les cultures dont le $\mathrm{pH}$ est maintenu à 7 , donc dans les conditions où le système protéolytique est stable, la production de ce dernier cesse en même temps que la croissance. Cette corrélation entre la croissance et la synthèse des enzymes protéolytiques exocellulaires observée également chez $M$. freudenreichii (MCDonaLD, I96I) et dans le genre $A$ rthrobacter (HOFSTEN et TJEDER, 1965) est fréquemment rencontrée dans la production des enzymes exocellulaires (PoLLOCK, I962). Néanmoins, quand le milieu de culture a été enrichi en ions calcium, la synthèse du système protéolytique se poursuit lentement après l'arrêt de la croissance. D'autre part, des cellules prélevées pendant la phase exponentielle de croissance, sont le siège d'une forte activité de synthèse quand elles sont incubées dans une solution de peptone. Il s'avère donc que la corrélation rigoureuse entre la croissance et la production du système protéolytique n'existe que dans certaines conditions de culture caractérisées par le fait que le 
milieu de culture contient encore des quantités notables de glucose quand la croissance s'arrête. On pourrait donc en conclure que, dans ce cas, le glucose exerce un effet répresseur ou que l'arrêt de la croissance serait la conséquence d'un arrêt de toutes les synthèses et en particulier de celle du système protéolytique.

Il a été montré chez $M$. freudenreichii (MCDONALD, I962) et chez Mucor hiemalis (WANG, I967) que la protéase exocellulaire produite par ces organismes avait tendance à rester accrochée à la paroi cellulaire sous l'action de forces ioniques et qu'elle en était libérée par des concentrations relativement élevées en chlorure de sodium ou en d'autres sels. Le phénomène existe vraisemblablement aussi chez $M$. caseolyticus puisqu'il produit moitié moins d'enzymes protéolytiques quand le milieu ne contient pas de chlorure de sodium. Cette réduction est beaucoup moins forte que celle observée chez $M$. freudenreichii, probablement parce que le tampon phosphate supplée partiellement à l'absence du chlorure de sodium.

Le système protéolytique de $M$. caseolyticus est complètement inductible par un mélange de peptides et dans une très faible mesure par un mélange d'acides aminés. Il est à noter que le glucose ou les acides aminés n'ont pas d'effet inhibiteur sur la biosynthèse, contrairement à ce qui a été observé chez $M$. freudenreichii (MCDonaL, et Chambers, I966). A notre connaissance, l'induction d'une protéase par des peptides n'avait pas encore été mise en évidence. Elle est en tout cas conforme au mécanisme général d'induction des enzymes exocellulaires qui peuvent être induits aussi bien par des composés à faible poids moléculaire que par le substrat principal de l'enzyme, qui a fréquemment un poiđs moléculaire élevé (PoLrock, I962). Cependant, chez $M$. caseolyticus, les substrats principaux, les protéines, n'ont pas d'effet inducteur chez les cellules non proliférantes, vraisemblablement par suite de leur incapacité à pénétrer à l'intérieur de la cellule. En revanche, ces substrats stimulent la synthèse du système protéolytique par les cellules en croissance. Cette stimulation est facilement expliquée par la formation de peptides inducteurs consécutive à un début d'hydrolyse de la protéine, sous l'action du système protéolytique induit par les acides aminés présents dans le milieu ou par des peptides provenant de l'extrait de levure.

Le fait que la caséine est un meilleur inducteur pour les cellules en croissance que l'hydrolysat trypsique de caséine, tendrait à prouver que les peptides inducteurs les plus actifs sont ceux produits à partir de la caséine par le système protéolytique luimême. Si tel était bien le cas, on devrait conclure à une relation entre la structure chimique des peptides, qui reflète la spécificité d'action de l'enzyme, et leur activité inductrice. On pourrait alors envisager d'expliquer l'effet stimulant des peptides sur la croissance des bactéries lactiques par une induction par ces peptides de la synthèse de leurs systèmes protéolytiques.

Rę̧u pour publication en avril 1968.

\section{REMERCIEMENTS}

Nous exprimons notre reconnaissance à M. MocQuot pour l'intérât qu'il a porté à ce travail et pour son aide dans l'établiss əmənt du manuscrit. 


\section{SUMMARY}

SOME FACTORS AFFECTING THE PROTEINASE PRODUCTION

OF " MICROCOCCUS CASEOLYTICUS "

The influences of sodium chloride, glucose, nitrogen sources, $\mathrm{pH}$ of the medium, temperature and aeration on the proteinase production of Micrococcus caseolyticus were studied. A controlled $\mathrm{pH}$ technique is advisable to obtain extracellular proteinase.

In a complex medium, the production of extracellular proteinase depended on growth rate, and the productivity of the enzyme on aeration. Glucose induced an increase in growth rate and proteinase production but the resulting acidification of the medium is responsible for considerable inactivation of the enzyme; the $\mathrm{pH}$ is to be maintained at 7.0.

Amino acids induced little extracellular proteinase ; in resting cells, proteins are not inducers. Peptides induced a considerable amount of extracellular proteinase. Proteinase formation is not repressed by amino acids or glucose.

\section{RÉFÉRENCES BIBLIOGRAPHIQUES}

Anson M.L., 1938. The estimation of pepsin, trypsin, papain, and cathepsin with hemoglobin. J. Gen.Physiol., 22, 79-89.

BAIRD-PARKER A. C., I963. A classification of micrococci and staphylococci based on physiological and biochemical tests. J. Gen. Microbiol., 80, 409-427.

CoLOBERT L., RocQuet G., I957. Position taxonomique de Micrococcus lysodeikticus et de Coccus P. Caractère contingent de la sécrétion de protéinase chez certaines espèces du genre Sarcina. Ann. Inst. Pasteur, 88, $663^{-670}$.

Gorini L., Fromageot C., 1950. Les facteurs physiologiques conditionnant la présence de protéinase dans les cultures de Micrococcus lysodeikticus. Biochim. Biophys. Acla, 5, 524-534.

Hofsten B. V., TJEDER CH., I965. An extracellular proteolytic enzyme from a strain of Arthrobacter. I. Formation of the enzyme and isolation of mutant strains without proteolytic activity. Biochim. Biophys. Acta, 110, 576-584.

HUSAIN I., MCDONALD I. J., 1958. Characteristics of an extracellular proteinase from Micrococcus freudenreichii. Can. J. Microbiol., 4, 237-242.

McDonald I. J., 196r. Proteinase production in relation to growth of a Micrococcus species. Can. J. Microbiol., 7, III-1I7.

MCDoNaLD I. J., 1962. Location of proteinase in cells of a species of Micrococcus. Can. J. Microbiol., 8, 785-794.

MCDoNALD I. J., Chambers A. K., 1966. Regulation of proteinase formation in a species of Micrococcus. Can. J. Microbiol., 12, I1 75-1 185 .

Pollock M. R., I962. Exoenzymes. In Gunsalus I. C. et Stanier R. Y., The Bacteria, Vol., 4, i $21-=78$. Academic Press, New York.

PozNANSKI S., LENOIR J., Mocquot G., 1965. La protéolyse de la caséine par les enzymes intracellulaires de certaines bactéries. Le lait, 441-442, 3-26.

Soerensen M., Haugaard G., I933. Bioch. Zeit., 260, 247. In Lotseleur J. Techniques de laboratoire, Masson et Cie Éditeurs, Paris, 1963 .

WANG H. L., 1967. Release of proteinase from mycelium of Mucor hiemalis. J. Bacteriol., 98, I 794- I 799. 